\title{
Patentes Farmacêuticas e Acesso a Medicamentos: Regras Comerciais, Direito à Saúde e Direitos Humanos ${ }^{* *}$
}

\author{
PHARMACEUTICAL PATENTS AND ACCESS TO DRUGS: TRADE \\ RULES, RIGHTTO HEALTH AND HUMAN RIGHTS
}

Carlos Alberto Polônio ${ }^{(\star *)}$

\section{RESUMO}

A aprovação do acordo TRIPS ao final da Rodada Uruguai do GATT resultou na ampliação da proteção dos chamados direitos de propriedade intelectual, a ponto de o debate sobre a proteção das patentes farmacêuticas, o direito à saúde e de acesso a medicamentos ter repercutido em diversos foros internacionais, como a Organização Mundial do Comércio, as Nações Unidas e a Organização Mundial da Saúde, dentre outros, além de ter contado com ampla mobilização de organizações não-governamentais. Tal mobilização decorreu da criação de obrigações que limitaram a capacidade dos países em desenvolvimento na implementação de políticas públicas na área da saúde, principalmente de programas de distribuição gratuita de medicamentos para doenças como a AIDS, que dependem substancialmente da importação de medicamentos (anti-retrovirais) para sua manutenção. A "Declaração sobre o Acordo TRIPS e a Saúde Pública", aprovada na Conferência Ministerial da OMC, realizada em Doha (2001), é resultado de um consenso a respeito da necessidade de limitar a proteção das patentes farmacêuticas para garantir o direito à saúde (acesso a medicamentos), tendo introduzido importante interpretação a respeito da limitação dos direitos dos titulares de patentes frente ao direito de os Estados adotarem políticas públicas na área da saúde.

(*) Este artigo é um sumário da dissertação de mestrado do autor, denominada "Proteção jurídica das patentes farmacêuticas no Brasil e sua adequação ao Acordo TRIPS: direito à saúde a acesso a medicamentos" (FADUSP, 2006), que contém a reprodução de passagens do referido trabalho acadêmico. (**) Graduado em Ciências Sociais e Direito pela Universidade de São Paulo (USP), mestre em Direito Internacional pela Faculdade de Direito da USP e professor do curso de Relações Internacionais do UniFMU.E-mait.<ca-polonio@uol.com.br>.Recebido em 20.7.06. Aprovadoem 6.9.06. 
Acesso a Medicamentos; Direito à Saúde; Patentes Farmacêuticas; Políticas Públicas; Propriedade Intelectual.

\section{ABSTRACT}

The approval of the TRIPS agreement at the end of the Uruguay Round of the GATT resulted in an enlargement of the protection of the copyright, in a way that the discussions on the protection of the pharmaceutical patents, the right to health and the access to medicines have repercussions in several international forums, such as World Trade Organization, United Nations and the World Health Organization. This subject has also involved different non-governmental organizations. Such mobilizations resulted of the creation of obligations that had limited the capacity of the developing countries to implement public politics in the area of public health, mainly the programs of free distribution of drugs for diseases such as AIDS that depend substantially on the medicine importation for its maintenance. The "Declaration on TRIPS Agreement and the Public Health", approved in the Ministerial Conference of the WTO, carried through in Doha (2001), is resulted of a consensus regarding the necessity to limit the protection of the pharmaceutical patents in order to guarantee the right to health (access to medicines), having introduced important interpretation regarding the limitation of the rights of the titleholders of patents facing to the right of the States to adopt public politics in the area of public health.

\section{Key words:}

Access to Medecines; Intellectual Property; Pharmaceutical Patents; Public Politics; Right to Health.

\section{INTRODUÇÃO}

A proteção das patentes farmacêuticas e a necessidade de acesso a medicamentos de populações sem ou com baixa renda conduzem a uma importante indagação relacionada à função da propriedade intelectual: como se alcançar uma fórmula viável para conferir maior flexibilidade na aplicação das regras do acordo TRIPS ${ }^{(1)}$ ? Essa questão é fundamental para se enten-

(1) TRIPS é a sigla em inglês que significa Trade Related Intellectual Property Rights (Acordo sobre Aspectos dos Direitos de Propriedade Intelectual Relacionados ao Comércio). Aprovado como Anexo 1C da Ata Final da Rodada Uruguai do GATT, em 15 de dezembro de 1993, trata-se de um tratado multilateral que incorporou todas as convenções sobre propriedade intelectual existentes até então, vinculando a matéria ao comércio internacional. 
der os motivos que levaram a implementação do acordo TRIPS a se transformar em objeto de debate que envolveu (e continua a envolver) diversos atores internacionais, como Organização das Nações Unidas (ONU), Organização Mundial da Propriedade Intelectual (OMPI), Organização Mundial da Saúde (OMS) e organizações não-governamentais (ONGs), num amplo esforço para se estabelecer padrões menos restritivos para a propriedade intelectual, no intuito de atender principalmente às necessidades de desenvolvimento de países pobres e a observância de certos direitos fundamentais, como o direito à saúde, por exemplo.

Basicamente, as posições dos países se dividem entre os que desejam manter ou ampliar o atual sistema de proteção da propriedade intelectual e os que criticam esse sistema, apontando para a necessidade de reformas ou até mesmo de sua extinção. Essas posições, por sua vez, refletem modos distintos de abordagem da propriedade intelectual, mas que estão relacionados aos limites e às finalidades dessa proteção a partir da adoção do acordo TRIPS, ao final da Rodada Uruguai do GATT - sigla em inglês de General Agreement on Tariffs and Trade; ou em português, Acordo Geral sobre Tarifas e Comércio - em 1994, configurando-se como uma espécie de conflito de interesses. Nesse sentido, há uma clara oposição entre os países que defendem a aplicação sem restrições do TRIPS e os que defendem maior flexibilidade na aplicação do Acordo, de forma a equilibrar suas regras e não restringir o uso legítimo de políticas públicas voltadas às necessidades básicas de atendimento das populações de países pobres, ao desenvolvimento econômico e à efetivação dos direitos humanos.

O tratamento uniforme da propriedade intelectual expresso no TRIPS é, sem dúvida, um fator de profunda divergência, pois no caso das patentes ${ }^{(2)}$ vigora o mesmo grau de proteção (20 anos, no mínimo) para todos os países, independentemente de seu nível de desenvolvimento. Isso equivale, na prática, a aplicar as mesmas regras de proteção de patentes para países que têm realidades e necessidades econômicas e sociais absolutamente distintas, como por exemplo, Estados Unidos e Angola.

No caso específico das patentes farmacêuticas, a proteção uniforme é ainda mais questionável, na medida em que medicamentos são bens essenciais à qualidade e à manutenção da vida, além do que os direitos de patente representam um monopólio efetivo sobre a exploração econômica de uma invenção, na qual o titular tem poucas obrigações e dispõe de amplos direitos. Isso significa que o titular da patente não sofre concorrência e pode decidir quando, onde e qual quantidade produzirá do medicamento patenteado, além de contar com ampla liberdade de fixar o preço apenas de acordo com suas expectativas de lucro ou por conveniências.

(2) Na definição de Denis Borges Barbosa, "patente, na sua formulação clássica, é um direito, conferido pelo Estado, que dá ao seu titular a exclusividade da exploração de uma tecnologia" (BARBOSA, Denis Borges. Uma introdução à propriedade intelectual. Rio de Janeiro: Lumen Juris, 1998. v. 1). 
Os países desenvolvidos são hoje responsáveis por 95\% das invenções patenteadas, sendo que no setor de medicamentos essa concentração é ainda maior, aproximando-se da quase totalidade das patentes registradas. Não há dúvida, portanto, que existe um enorme desequilíbrio entre os chamados países produtores de tecnologia - em regra, desenvolvidos e industrializados - e aqueles consumidores de tecnologia - paises em desenvolvimento ou menos adiantados (de média e baixa industrialização, respectivamente) - e que, por isso mesmo, dependem quase exclusivamente da importação de novas tecnologias e de novos produtos para atender seus mercados internos.

O Brasil é um dos países que dependem em grande medida da importação de insumos químicos e de determinados medicamentos para atender à demanda gerada por suas indústrias farmacêuticas e por suas políticas públicas de saúde, como é o caso do Programa Nacional DST/AIDS, que figura entre os mais importantes e bem-sucedidos programas de tratamento e distribuição gratuita de anti-retrovirais.

Iniciado em $1986^{(3)}$, o Programa DST/AIDS brasileiro encontra-se hoje diante de um impasse, qual seja, o de que poderão faltar nos próximos anos recursos públicos para financiar a sua manutenção. Há, portanto, um problema de sustentabilidade do Programa, baseado no fato de que as novas drogas para tratamento da $\operatorname{AIDS}^{(4)}$, desenvolvidas e patenteadas pelos laboratórios multinacionais, têm preços cada vez mais elevados, inviabilizando progressivamente a importação desses medicamentos em razão da dotação orçamentária para a área da saúde pública ser cada vez mais restrita( ${ }^{(5)}$.

Se no Brasil há uma preocupação real com a manutenção da distribuição de medicamentos para atender aos pacientes de AIDS e outros programas do gênero, na maioria dos países da África, alguns da América Latina e vários da Ásia e do Leste Europeu a ajuda humanitária tem sido a única maneira de proporcionar o acesso a suas populações aos medicamentos anti-retrovirais. Além da AIDS, esses países ainda dependem da colaboração internacional para atenuar outros problemas que matam anualmente milhões de pessoas, como a fome, os conflitos internos, as guerras com países vizinhos e outras doenças que já foram erradicadas nos países

(3) Embora o Programa DST/AIDS tenha tido início em 1986, foi a experiência de profissionais da Secretaria de Saúde do Estado de São Paulo, a partir de 1983, que serviu de base para o lançamento do programa em escala nacional pelo Ministério da Saúde.

(4) A sigla AIDS corresponde à abreviação do termo inglês Acquired Immune Deficiency Syndrome. Em português ou espanhol utiliza-se a sigla SIDA (Síndrome da Imunodeficiência Adquirida).

(5) Dados do Ministério da Saúde apontam que, no ano de 2004, as despesas com importação de medicamentos anti-retrovirais foram da ordem de $R \$ 1,050$ bilhão, contra $R \$ 660$ milhões gastos no ano de 2003 , considerando-se o orçamento total de $R \$ 3,4$ bilhões para o custeio de todos os serviços de saúde do Ministério. Disponível em: <www. aids.gov.br>. Acesso em: 28 set. 2005. 
desenvolvidos, as chamadas "doenças negligenciadas"(6) (malária, tuberculose, doença do sono, leishmaniose, dentre outras).

É notório que, do ponto de vista da saúde pública, a maioria desses países não conta com infra-estrutura física e de pessoal (saneamento básico, instalações hospitalares etc.), além de não dispor de recursos suficientes para fazer frente às importações de medicamentos e combater as doenças, dependendo quase exclusivamente de ajuda humanitária. A essas dificuldades somam-se os elevados preços dos medicamentos praticados pelos laboratórios farmacêuticos multinacionais que, ao não fazerem distinção entre os preços praticados nos seus mercados de origem (paises desenvolvidos) e dos demais países, criam ainda mais restrições de acesso a medicamentos. Por isso, uma das principais críticas dirigidas ao acordo TRIPS é que suas regras conseguiram ampliar ainda mais os direitos dos titulares de patentes sem que tivessem sido criados mecanismos compensatórios para beneficiar os consumidores de produtos patenteados essenciais, como são os medicamentos, aplicando-se exclusivamente o critério econômico(7). Ocorre, todavia, que num ambiente econômico globalizado e de competição, as patentes são exceções, pois garantem aos seus titulares o direito a uma verdadeira "reserva de mercado", com custos econômicos e sociais incalculáveis para a sociedade. Não há, portanto, competição ou concorrência onde só existe um titular com direito a usufruir o monopólio de explorar economicamente o objeto da patente pelo prazo mínimo 20 anos $^{(8)}$.

O acordo TRIPS reforçou esse modelo ao adotar a premissa de que o mesmo grau de proteção da propriedade intelectual pode e deve ser aplicado a países com níveis diferentes de desenvolvimento, pois isso atrairia novos investimentos, estimularia a dinamização da economia e provocaria a transferência de tecnologia. Na prática, porém, esse modelo de proteção do TRIPS tem sido muito criticado e não apresentou os resultados anunciados, pois os custos de sua manutenção para os países que dependem da

(6) São consideradas doenças negligenciadas, pois não despertam interesse comercial dos laboratórios multinacionais, sob a justificativa questionável de que não existe mercado consumidor viável e, conseqüentemente, não há interesse em pesquisar e desenvolver drogas para combater essas doenças.

(7) No caso específico dos medicamentos, "Essa situação significa um acesso a esses 'medicamentosmercadorias' limitado àqueles 'pacientes-consumidores' com poder aquisitivo suficiente para comprá-los ou recebê-los, através de sistema de seguro saúde, público ou privado. Ou seja, boa parte da humanidade não se enquadra nesse caso e encontra-se excluída do mercado de medicamentos patenteados" (LOTROWSKA, Michel. Panorama internacional contemporâneo do acesso a anti-retroviral. In: PASSARELLI, Carlos André; PARKER, Richard; TERTO JR., Cristina Pimenta e Veriano (Orgs.). AlDSe desenvolvimento: interfaces e políticas públicas. Rio de Janeiro: ABIA - Associação Brasileira Interdisciplinar de AIDS, 2003. p. 189).

(8) O acordo TRIPS prevê em seu art. 33 o prazo mínimo de 20 anos para proteção de uma patente, podendo esse prazo ser ampliado de acordo com a legislação de cada país. Porém, no Brasil, assim como em vários outros países, antes da vigência do TRIPS não havia proteção para as patentes farmacêuticas. Isso equivale a dizer que a lei anterior de propriedade industrial (Lei $n .5 .772 / 71$ ) não reconhecia o direito de patente para os fármacos de um modo geral. 
importação de tecnologias e de produtos patenteados têm, pelo contrário, inviabilizado a instalação de novas indústrias e restringido cada vez mais a importação de bens essenciais para suas populações.

O resultado do desequilíbrio entre direitos e obrigações no TRIPS gerou uma pressão no interior da Organização Mundial do Comércio (OMC) por parte de países em desenvolvimento - com destaque para a atuação do Brasil e da Índia - que se sentiram prejudicados com a possibilidade de verem reduzidas as ações de suas políticas públicas, especialmente na área da saúde. Nesse sentido, por iniciativa de um grupo de países da África, - Conselho sobre o TRIPS, órgão da estrutura da OMC, reuniu-se pela primeira vez em 20 de junho de 2001 para discutir especificamente o tema das patentes farmacêuticas, quando então ficou clara a divisão de posições entre dois grupos de interesse, ao apresentarem relatórios diferentes no final da reunião. Pelo lado dos países em desenvolvimento, além do Grupo Africano (países africanos membros da $\mathrm{OMC}$ ), subscreveram o relatório os seguintes países: Barbados, Bolívia, Brasil, República Dominicana, Equador, Honduras, Índia, Indonésia, Jamaica, Paquistão, Paraguai, Filipinas, Peru, Sri Lanka, Tailândia e Venezuela, que contou ainda com o apoio de diversas organizações não-governamentais, como Médicos Sem Fronteiras, Oxfam e Consumers International, dentre outras.

Basicamente, o grupo dos países em desenvolvimento "pediam o reconhecimento de que o Acordo TRIPS não afetaria, de qualquer forma, o direito legítimo dos membros da OMC de formularem e implementarem políticas de proteção da saúde pública. À OMC faltaria a competência para tanto, o que deveria permanecer sob a alçada de outros organismos internacionais, como a Organização Mundial da Saúde. A preocupação era, em grande parte, derivada das tentativas de bloqueio de medidas de saúde pública nos casos sul-africano e Estados Unidos vs. Brasil. Sugeriu-se ainda a inclusão do tema na agenda da Conferência Ministerial de Doha"(9).

No outro grupo, formado por países desenvolvidos, "a União Européia também apresentou relatório ao Conselho sobre o TRIPS, abrindo espaço para a discussão sobre a interpretação dos dispositivos do TRIPS. A posição do bloco europeu era de que o Acordo TRIPS não poderia ser considerado causador da crise sanitária nos países em desenvolvimento, mas, nem por isso, deveria impedir ou retardar o combate a essa crise, cuja necessidade seria urgente e que dependeria de outras medidas e políticas econômicas e sociais. Além disso, a União Européia ofereceu interpretações diversas das postuladas pelos países em desenvolvimento dos arts. $7^{\circ}, 8^{\circ}$, 30,31 e 39 do TRIPS"(10).

(9) SANTOS, Denis Ishikawa dos. Patentes farmacêuticas e acesso a medicamentos: da Rodada Uruguai à Declaração de Doha sobre o Acordo TRIPS e Saúde Pública. 2004. f. 74. Tese (Tese Láurea Curso de Graduação) - Faculdade de Direito, Universidade de São Paulo, São Paulo, 2004.

(10) ld., loc. cit. 
Diante da divergência de opiniões a respeito da interpretação e alcance das regras do acordo TRIPS, agendou-se nova reunião do Conselho sobre o TRIPS para 19 de setembro de 2001, na qual foram discutidas duas minutas de declaração ministerial. Tais minutas refletiram praticamente as mesmas posições anteriores, ou seja, os países em desenvolvimento defendiam a prorrogação de prazos para a aplicação do acordo TRIPS e resistiam a tratar medidas de saúde pública no âmbito do sistema de disputas da OMC. Já os países desenvolvidos aceitavam a flexibilização das regras do TRIPS apenas para algumas doenças (AIDS, tuberculose e malária), enquanto os países em desenvolvimento focavam nos objetivos gerais de saúde pública. As duas minutas de declaração ministerial viriam a ser novamente debatidas e negociadas durante a realização da Conferência Ministerial da OMC em Doha, prevista para ocorrer em novembro do mesmo ano (2001).

Após meses de intensos debates e negociações, em novembro de 2001, ao final da Conferência Ministerial de Doha foi aprovada a "Declaração sobre o Acordo TRIPS e a Saúde Pública", que tratou especificamente da questão das patentes farmacêuticas e sua relação com a saúde pública, ressaltando a importância de se implementar e interpretar o acordo TRIPS de maneira consistente com a defesa da saúde pública, promovendo o acesso das pessoas aos medicamentos e o incentivo à pesquisa e ao desenvolvimento de novas drogas. Documento de caráter interpretativo do acordo TRIPS, a "Declaração sobre o Acordo TRIPS e a Saúde Pública" reconheceu que "o Acordo pode e deve ser interpretado e implementado de modo a implicar apoio ao direito dos Membros da OMC de proteger a saúde pública e, em particular, de promover o acesso de todos aos medicamentos" ( $\left(4^{2}\right)$ e, ainda, para "que os membros da OMC com pouca ou nenhuma capacidade de produção no setor farmacêutico possam enfrentar dificuldades para a efetiva utilização do licenciamento compulsório(11) previsto no Acordo TRIPS" (§ 6).

A "Declaração sobre o Acordo TRIPS e a Saúde Pública" é um documento fundamental de interpretação dos limites da proteção dos direitos de propriedade intelectual, especialmente em relação às patentes farmacêuticas e à adoção de políticas públicas na área da saúde. Nesse sentido, por meio de deliberação aprovada durante a $4^{\text {a }}$ Conferência Ministerial da OMC, realizada em Doha, e em consonância com diversas Convenções sobre direitos humanos, reconheceu-se que o direito à saúde prevalece quando confrontado com os direitos de propriedade intelectual.

O contexto político internacional no qual a Conferência de Doha foi realizada não pode ser desconsiderado, até porque o ano de 2001 , além

(11) Na definição de Cícero Gontijo: "A licença compulsória (também chamada obrigatória) é um dos instrumentos de que o Estado pode se utilizar para intervir sobre o monopólio de uma patente, sempre que o interesse público o exija" (GONTIJO, Cícero Ivan Ferreira. Propriedade industrial no século XXI. direitos desiguais. Estudo realizado a pedido do Grupo de Trabalho de Propriedade Intelectual da Rede Brasileira pela Integração dos Povos - Rebrip, Instituto de Estudos Socioeconómicos - Inesc e Oxfam, jul. 2003. p. 36). 
do impacto mundial dos atentados de 11 de setembro em Nova lorque, foi de intensa mobilização dos países em desenvolvimento que, com apoio estratégico de ONGs de perfil humanitário, deram início à organização de um movimento em defesa de interesses comuns à defesa da saúde pública e do estabelecimento de uma nova agenda para a $\mathrm{OMC}$, mais adaptada às necessidades especiais desses países. Portanto, a partir de Doha evidenciou-se uma reação dos países em desenvolvimento para tentar equilibrar as negociações comerciais na OMC, evitando retrocessos e provocando a discussão de temas até então sem progressos negociais, como, por exemplo, o fim dos subsídios agrícolas nos países desenvolvidos.

É inegável que com a aprovação da "Declaração sobre Acordo o TRIPS e a Saúde Pública" houve, em relação aos objetivos de saúde pública, substancial avanço na interpretação do TRIPS em favor do máximo aproveitamento de suas flexibilidades. O estabelecimento de uma "regra de hierarquização" dos objetivos do direito internacional da propriedade intelectual representou, numa análise genérica, a reafirmação da prevalência dos direitos humanos nas relações econômicas internacionais.

A dignidade inerente a todos os seres humanos e a igualdade entre os homens são princípios basilares dos direitos humanos, dos quais derivam direitos inalienáveis, como o direito à vida, à liberdade, à integridade física, à segurança e à saúde, dentre outros. Sob essa ótica, o direito à saúde é visto como um direito social que requer uma prestação positiva do Estado, no sentido de garantir aos cidadãos acesso a serviços e políticas de prevenção e tratamento de doenças. Por isso, "Como conseqüência primeira do direito à saúde (direito de estar são), deve-se agregar o direito à prevenção de doenças (direito de permanecer são). Assim, o Estado é responsável, tanto por manter o indivíduo são, desenvolvendo políticas de saúde, como para evitar que ele se torne doente. O direito à prevenção de doenças é, conseqüentemente, parte do direito à saúde" (12).

No âmbito do direito internacional há vários instrumentos sobre direitos humanos que reconhecem, direta ou indiretamente, o direito à saúde. O primeiro exemplo que utilizamos está no inciso 1 do art. 25 da Declaração Universal dos Direitos do Homem (1948), ao dispor que: "Toda pessoa tem direito a um padrão de vida capaz de assegurar a si e a sua família saúde e bem-estar, inclusive alimentação, vestuário, habitação, cuidados médicos e os serviços sociais indispensáveis ...".

Outro exemplo está contido no Pacto Internacional dos Direitos Econômicos, Sociais e Culturais ${ }^{(13)}$ ao estabelecer em seu art. 12, incisos 1 e 2, que:

(12) ARAÚJO, Luiz Alberto David. A proteção constitucional das pessoas portadoras de deficiência. 2. ed. Brasília: Corde, 1997.p. 53-54.

(13) Aprovado pela Assembléia Geral das Nações Unidas, em 16 de dezembro de 1966, foi promulgado no Brasil por meio do Decreto n. 592, de 6 de dezembro de 1992. 
"1. Os Estados-partes no presente Pacto reconhecem o direito de toda pessoa de desfrutar o mais elevado nível possível de saúde física e mental. 2. As medidas que os Estados-partes no presente Pacto deverão adotar, com o fim de assegurar o pleno exercício desse direito, incluirão as medidas que se façam necessárias para assegurar: a) a diminuição da mortandade e da mortalidade infantil, bem como o desenvolvimento sadio das crianças; b) a melhoria de todos os aspectos de higiene do trabalho e do meio ambiente; c) a prevenção e o tratamento das doenças epidêmicas, endêmicas, profissionais e outras, bem como a luta contra essas doenças; d) a criação de condições que assegurem a todos assistência médica e serviços médicos em caso de enfermidade".

Já o Protocolo Adicional à Convenção Americana sobre Direitos Humanos em Matéria de Direitos Econômicos, Sociais e Culturais ${ }^{(14)}$ dispõe sobre o direito à saúde nos incisos 1 e 2 de seu art. 10: "(1) Toda pessoa tem direito à saúde, compreendendo-se como saúde o gozo do mais alto nível de bem-estar físico, mental e social; 2) A fim de tornar efetivo o direito à saúde, os estados-partes comprometem-se a reconhecer a saúde como bem público e, especialmente, a adotar as seguintes medidas para garantir esse direito: a) assistência primária à saúde, entendendo-se como tal a assistência médica essencial ao alcance de todas as pessoas e famílias da comunidade; b) extensão dos benefícios dos serviços de saúde a todas as pessoas sujeitas à jurisdição do Estado; c) total imunização contra as principais doenças infecciosas; d) prevenção e tratamento das doenças endêmicas, profissionais e de outra natureza; e) educação da população com referência à prevenção e ao tratamento dos problemas da saúde; e f) satisfação das necessidades de saúde dos grupos de mais alto risco e que, por sua situação de pobreza, sejam mais vulneráveis."

Revelam-se igualmente importantes as ações e decisões (resoluções) das Nações Unidas e da Organização Mundial da Saúde. É preciso dizer, adicionalmente, que o surgimento nas últimas décadas de novas epidemias e a explosão do número de óbitos por doenças como a AIDS, malária e tuberculose fez surgir a necessidade de se incluir a efetivação do direito à saúde e de acesso a medicamentos como temas prioritários entre as chamadas Metas do Milênio(15). Em seguida, faremos um breve histórico da atuação

(14) Apesar de ter sido aprovada e aberta à assinatura em 22 de novembro de 1969 e vigente desde 18 de julho de 1978, o Brasil só veio a aderir à Convenção Americana sobre Direitos Humanos em 25 de setembro de 1992, depois da promulgação do Decreto n. 678, de 6 de novembro de 1992. Já o Protocolo de São Salvador, foi adotado durante a XVIII Assembléia Geral da Organização dos Estados Americanos, em São Salvador, a 17 de novembro de 1988, e foi aprovado no Brasil por meio do Decreto Legislativo n. 56, de 19 de abril de 1995.

(15) As Metas do Milênio fazem parte do Projeto do Milênio da Organização das Nações Unidas (ONU), sendo que o trabalho referente à $6^{a}$ Meta do Milênio - 'combate ao HIVIAIDS, malária e outras doenças' está sendo realizado por uma "força-tarefa" que, por sua vez, está dividida em quatro grupos de trabalho, todos voltados ao combate ao HIVIAIDS, à malária e à tuberculose e ao acesso a medicamentos. 
dessas duas organizações internacionais (ONU e OMS) nos últimos cinco anos, relacionada ao tema do direito à saúde e ao acesso a medicamentos.

No mês de abril de 2001 realizou-se a 57ª sessão ordinária da Comissão sobre Direitos Humanos da ONU, que tratou especialmente desse assunto e adotou, por 52 votos a favor, uma abstenção (Estados Unidos) e nenhum voto contrário, a Resolução n. 2001/33, de iniciativa do Brasil, denominada "Acesso a Medicamentos no Contexto de Pandemias como o HIV/ AIDS". Nesse sentido, "A Resolução da Comissão sobre Direitos Humanos reconheceu que o acesso aos medicamentos é elemento fundamental para a plena realização do direito de todos aos melhores padrões de saúde física e mental. Além disso, a Comissão pediu aos Estados que evitassem as medidas que impedissem ou limitassem o acesso igualitário aos medicamentos necessários ao tratamento de pandemias como a AIDS. Também convocou os Estados para que adotassem leis e regulamentos (em conformidade suas obrigações internacionais) e outras medidas positivas para promover o efetivo acesso àqueles medicamentos, bem como que aplicassem os tratados internacionais de forma a facilitar as políticas de saúde pública de outros países que promovessem a redução dos preços dos medicamentos e tecnologias médicas"(16).

Ainda no âmbito das Nações Unidas (17), entre os dias 25 a 27 de junho de 2001, realizou-se em Nova York a 1 Sessão Especial das Nações Unidas sobre HIVIAIDS (UNGASS), no intuito de criar uma estratégia global na luta contra a AIDS, tanto no campo da prevenção como no campo do tratamento. Participaram dessa Sessão Especial representantes de cerca de 180 países, entre os quais o Brasil, cujo Ministro da Saúde fez um importante discurso a favor da produção local de medicamentos como forma de tornar mais barato o tratamento e, com isso, facilitar o acesso aos medicamentos a um número maior de pessoas. Na ocasião, debateu-se ainda a necessidade de criação de um fundo destinado a receber e administrar recursos para ações de combate à AIDS, o que depois veio a se concretizar por meio da instituição, no âmbito da própria ONU, do Fundo Global de Luta contra a AIDS, Tuberculose e Malária.

Além disso, "A Declaração [final da Sessão Especial] tratou de estabelecer metas para os países no combate à epidemia da AIDS nos níveis regio-

(16) SANTOS, Denis Ishikawa dos. op. cit., p. 68-69.

(17) É importante destacar que a partir de 1996 iniciaram-se as atividades do Programa Conjunto das Nações Unidas sobre HIVIAIDS - UNAIDS, por meio do intercâmbio de informações, do planejamento e do monitoramento conjunto das açōes em apoio à resposta nacional em HIVIAIDS. O UNAIDS é resultado de um trabalho coordenado que inclui outros membros: UNFPA - United Nations Population Fund, UNDP - United Nations Development Programme, UNICEF - United Nations Children's Fund, UNESCO - United Nations Educational, Scientific and Cultural Organization, UNODC - United Nations Office for Drug and Crime, WHO - World Health Organization, WORLD BANK, ILO - International Labor Organization. 
nal, nacional e local. Entre outros objetivos, o $§ 55$ da Declaração impôs aos Estados o dever de proporcionar a disponibilidade de medicamentos antiretrovirais, por meio de genéricos baratos e do desenvolvimento da capacidade industrial para produzi-los e levá-los à população, sem deixar de lado a cooperação internacional para o fortalecimento dos direitos de propriedade intelectual necessários à inovação"(18).

Após essas iniciativas, no dia 22 de abril de 2003, por meio da Resolução 2003/29 (Access to medication in the context of pandemics such as HIVIAIDS, tuberculosis and malaria), a Comissão sobre Direitos Humanos da ONU reafirmou e ampliou os compromissos anteriores expressos na Resolução 2001/33 (Access to medication in the context of pandemics such as HIVIAIDS).

Outras iniciativas importantes ocorreram no âmbito da Organização Mundial da Saúde quando, em 21 de maio de 2001, durante a 54" Assembléia Mundial de Saúde, aprovou-se a Resolução WHA54.11, denominada "Estratégia Farmacêutica da OMS", na qual foram realçados "os desafios relacionados com os acordos comerciais internacionais, 0 acesso aos medicamentos essenciais, a qualidade dos medicamentos e o uso racional dos mesmos, assim como a urgente necessidade de melhorar o acesso aos medicamentos requeridos para tratar problemas de saúde prioritários, como o paludismo, as enfermidades infantis, O HIV/AIDS e a tuberculose, entre outros".

Percebe-se que tanto a Resolução n. 2001/33, aprovada pela Comissão de Direitos Humanos da ONU, quanto a Resolução WHA54.11, da OMS, fazem referência expressa à necessidade de os tratados internacionais, de forma geral, serem implementados de modo a facilitar a aplicação de políticas públicas de saúde e de acesso aos medicamentos. A Resolução da OMS sustenta, inclusive, que "é preciso avaliar mais a fundo as repercussões dos acordos comerciais internacionais no acesso aos medicamentos essenciais ou em sua fabricação, assim como no desenvolvimento de novos medicamentos".

Em 18 de maio de 2002, durante a 55a Assembléia Mundial da Saúde, o tema de acesso a medicamentos veio a ser objeto de nova resolução da OMS. A Resolução WHA55.14 (Garantia de acessibilidade dos medicamentos essenciais) reafirmou a importância da "Declaração sobre o TRIPS e a Saúde Pública" e reforçou o consenso no âmbito da própria Organização Mundial de Saúde sobre a necessidade de se evitar as repercussões negativas dos acordos de comércio internacional para o acesso eqüitativo a todos os medicamentos, em particular os medicamentos essenciais.

(18) SANTOS, Denis Ishikawa dos. op. cit., p. 69. 
Nesse aspecto, é interessante observar como os temas comércio internacional e propriedade intelectual, especialmente no tocante às patentes farmacêuticas e saúde pública, não podem ser tratados sem que se considerem seus efeitos adversos, motivo pelo qual a própria OMS chamou a atenção para a necessidade de uma estratégia global e de cooperação entre os países e as organizações internacionais.

Na 56 ${ }^{\underline{a}}$ Assembléia Mundial da Saúde, especificamente no dia 28 de maio de 2003, foram adotadas duas novas resoluções relacionadas aos temas da patente farmacêutica e saúde pública. A primeira delas (Resolução WHA56.27), denominada "Direitos de propriedade intelectual, inovação e saúde pública", abordou a questão das "doenças negligenciadas", ou seja, aquelas doenças que embora atinjam grande parte da população mundial, principalmente em países pobres, não atraem o interesse da indústria farmacêutica para o desenvolvimento de medicamentos. Segundo dados constantes do texto da própria Resolução WHA56.27, "de 1.400 novos produtos desenvolvidos pela indústria farmacêutica entre 1975 e 1999, só treze estavam destinados ao tratamento de enfermidades tropicais e três à tuberculose".

Considerando que $90 \%$ das vendas mundiais de produtos farmacêuticos são feitas nos países desenvolvidos e que $90 \%$ das 14 milhões de enfermidades infecciosas produzidas no mundo estão localizadas nos países em desenvolvimento e nos países de menor desenvolvimento relativo, não é difícil concluir que há insuficiente pesquisa e desenvolvimento de medicamentos voltados a atender as chamadas "enfermidades desatendidas", ou "enfermidades relacionadas à pobreza", como são citadas no próprio texto da Resolução WHA56.27. Essa mesma Resolução da OMS acrescenta, ainda, que "o setor farmacêutico deve responder às necessidades de saúde pública e não só as possibilidades de obter benefícios comerciais", até porque "as inovações e as descobertas em matéria de saúde devem estar à disposição de todos sem discriminação".

Quanto à Resolução WHA56.30, também de 28 de maio de 2003, tratou de estabelecer diretrizes para uma "Estratégia mundial do setor sanitário para o HIVIAIDS". Tal Resolução procurou definir uma "resposta global" contra a epidemia do HIVIAIDS por meio do reforço da capacidade do setor sanitário a fim de: "a) absorver e gerir os recursos; b) melhorar o planejamento, o estabelecimento de prioridades, o desenvolvimento de recursos humanos, a gestão dos programas, a aplicação e integração de intervenções chave, a mobilização de organizações não governamentais e a segurança da qualidade e sustentabilidade dos serviços; c) apoiar as pesquisas como parte das respostas nacionais".

Outro importante aspecto da Resolução WHA56.30 da OMS diz respeito ao tratamento da saúde pública diante das flexibilidades reconhecidas pelo Acordo TRIPS, no sentido de que "os interesses de saúde pública têm uma importância primordial nas políticas tanto farmacêuticas como sanitárias, 
reconhecendo as dificuldades que enfrentam os países em desenvolvimento para o uso efetivo das licenças obrigatórias de conformidade com a Declaração relativa ao Acordo sobre TRIPS e Saúde Pública (Declaração de Doha), e, quando proceda, usem as flexibilidades do Acordo TRIPS para satisfazer as necessidades dos países em desenvolvimento em matéria de medicamentos contra o HIV/AIDS".

Posteriormente, em 22 de maio de 2004 adotou-se na $57^{\text {a }}$ Assembléia Mundial de Saúde a Resolução WHA57.14 (Expansão do tratamento e a atenção no marco de uma resposta coordenada e integral ao HIV/AIDS), que, entre outros temas, ressaltou "a estratégia 'três milhões para 2005' do Diretor Geral [da OMS], encaminhada com o objetivo de ajudar os países em desenvolvimento, como da estratégia mundial integral do setor sanitário para o HIV/AIDS da OMS, a conseguirem que três milhões de pessoas afetadas pelo HIVIAIDS tenham acesso a tratamento anti-retroviral até o final de 2005, e destaca a importância, sobretudo para a OMS, de mobilizar recursos financeiros dos Estados e outros doadores a fim de poder alcançar essa meta".

Além disso, a Resolução WHA57.14 solicitou aos Estados-membros que "considerem, quando proceda, a possibilidade de adaptar a legislação nacional a fim de aproveitar plenamente as flexibilidades previstas no Acordo TRIPS" e que também "propugnem que os acordos comerciais bilaterais tenham em conta as flexibilidades previstas no Acordo TRIPS da OMC e reconhecidas pela Declaração Ministerial de Doha relativa ao Acordo TRIPS e a Saúde Pública".

A nosso ver, a "Declaração sobre o Acordo TRIPS e a Saúde Pública" representa mais do que a simples constatação de que "o Acordo TRIPS não impede nem deverá impedir que os Estados-membros adotem medidas para proteger a saúde pública". Trata-se do reconhecimento, pela própria $\mathrm{OMC}$, da prevalência do direito à saúde sobre o direito de patente (direito à propriedade).

É incompleta a análise segundo a qual as únicas tarefas para facilitar o tratamento de enfermidades e democratizar o acesso a medicamentos passam pela revisão ou flexibilização do acordo TRIPS e por melhorias na infra-estrutura médica e social internas. Doenças como a AIDS e outras enfermidades (malária, tuberculose, dentre outras) têm sido negligenciadas pelos grandes laboratórios farmacêuticos multinacionais, pois atingem principalmente as pessoas pobres de países ricos ou pessoas pobres de países pobres, tornando-as vítimas de uma constatação cruel: ou não há incentivo ou não há recursos destinados a desenvolver novas drogas para atenuar os efeitos ou curar essas enfermidades.

"Um estudo de Amir Attaran e Lee Gillespie-White ${ }^{(19)}$ procura imputar a outros fatores a falta de acesso a medicamentos anti-retrovirais no continente

(19) Do patents for antiretroviral drugs constrain access to AIDS treatment in Africa? Disponivel em <http:// www.iipi.org/activities/Research/antiretroviral_article.pdf>. Acesso em: 22.dez.2005. 
africano. Tendo procurado em 53 países africanos o status de 15 medicamentos anti-retrovirais (produzidos por 8 dos maiores grupos farmacêuticos do mundo e utilizados, em diversas combinações de três, no tratamento da AIDS), os pesquisadores descobriram que, na maioria deles, poucos ou nenhum daqueles medicamentos estão sob proteção de patente ou de pedido de patente, e que apenas em dois países (África do Sul e Zimbabue) mais da metade desses medicamentos estão patenteados. Isso permitiria, em 52 dos países africanos pesquisados, a administração de tratamentos contra a AIDS baseados em diversas opções de regimes compostos de três anti-retrovirais não patenteados, ou de dois não patenteados combinados com um patenteado"(20).

No caso da Índia(21), por exemplo, que é o país que fabrica genéricos de anti-retrovirais em maior quantidade e a preços mais baixos, não há uma política estatal integrada que garanta acesso dos pacientes de AIDS a esses medicamentos. Somente em abril de 2004 o governo da Índia deu início - e apenas em Nova Délhi - ao processo de distribuição de anti-retrovirais para cerca de 100.000 pessoas. Esse exemplo mostra como mesmo a fabricação local de medicamentos em larga escala - neste caso, produção de versões genéricas de medicamentos sob proteção de patentes - sem uma política integrada de saúde pública não é suficiente para enfrentar o avanço de epidemias, pois a fabricação de drogas a preços baixos não se traduz necessariamente em melhoria de acesso da população aos medicamentos, que depende, como dissemos, de outras variáveis (como infra-estrutura médica e social básicas, médicos e enfermeiros bem treinados e, principalmente, pacientes motivados e bem informados)(22).

Em relação às corporações farmacêuticas, elas concentram suas pesquisas prioritariamente em doenças típicas de países ricos (cardiopatia, obesidade, diabetes etc.), pois o mercado consumidor tem alto poder aquisitivo e pode assimilar os preços (altos) dos medicamentos praticados por essas empresas. Já as doenças de países pobres são chamadas de doenças negligenciadas porque falta interesse às corporações farmacêuticas em

(20) SANTOS, Denis Ishikawa dos. op. cit., p. 24.

(21) A Índia aproveitou-se plenamente do prazo de transição facultado no acordo TRIPS aos países em desenvolvimento para proteção das patentes farmacêuticas, prorrogando ao máximo sua implementação. Com isso, o país só passou a proteger as patentes farmacêuticas registradas a partir de $1^{8}$ de janeiro de 2005, quando começou a vigorar a lei indiana sobre a matéria.

(22) "O sistema de Plé um dos vários fatores que afetam o acesso da população de baixa renda à saúde. Outras limitações importantes ao acesso a medicamentos em países em desenvolvimento são a falta de recursos e a ausência de uma infra-estrutura de saúde adequada (incluindo hospitais, clínicas, profissionais de saúde, equipamentos e suprimento adequado de drogas) para administrar medicamentos de maneira segura e eficaz" (Integrando Direitos de Propriedade Intelectual e Política de Desenvolvimento. Relatório elaborado pela Comissão para Direitos de Propriedade Intelectual do Ministério Desenvolvimento Internacional do Reino Unido. Londres, set. 2002. p. 14. Disponivel em: <http:/hww.jprcommission.org>). 
investir em pesquisas para desenvolver novas drogas para tratamento dessas doenças, sobretudo pelo fato de não haver por parte dos potenciais consumidores dessas drogas renda suficiente para adquiri-las.

Constata-se uma situação paradoxal na qual as "leis de mercado" não oferecem respostas às necessidades de grandes populações, ao mesmo tempo em que seria considerada absurda qualquer proposta no sentido de se criar mecanismos que obrigassem empresas a investirem uma parcela de seus lucros em novas drogas para tratamento de doenças típicas de países pobres. Portanto, uma parte do problema situa-se na linha de defesa por mudanças ou revisões de tratados internacionais em vigor, que claramente geram mais custos do que benefícios para os países em desenvolvimento, como é o caso do acordo TRIPS, outra linha de ação situa-se na criação de mecanismos efetivos (jurídicos e institucionais) de cooperação que vinculem e obriguem os países, principalmente os desenvolvidos, a aplicar nas relações internacionais os mesmos critérios e as mesmas políticas que adotam para suas populações, sem discriminação.

Por exemplo, a criação do Fundo Global de Luta contra a AIDS, Tuberculose e Malária é uma tentativa de suprir essa carência, embora, desde sua origem, a arrecadação de recursos para o Fundo esteja frustrando o atendimento de seus objetivos básicos. Paralelamente, e com o mesmo espírito de cooperação internacional, alguns países em desenvolvimento têm se organizado no sentido de criar estratégias comuns para doenças como a AIDS. Assim, em maio de 2004, Brasil, juntamente com Índia, China, Tailândia, África do Sul, Rússia, Nigéria e Uganda formaram um grupo para atuak em conjunto no âmbito da OMS, visando ao combate da AIDS e à defesa de posições em relação aos países ricos nos debates sobre as estratégias contra a doença, como acesso a medicamentos e preservativos, cooperação técnica, ações coordenadas para licenciamento compulsório de drogas produzidas por laboratórios multinacionais.

Existem ainda outras maneiras de contornar alguns dos obstáoulos aqui identificados em relação às patentes $\theta$ ao acesso a medicamentos. Trata-se de uma diferenciação que poderia ser introduzida adicionalmente no acordo TRIPS entre aqueles bens considerados essenciais e os demais tipos de bens para efeito de proteção patentária. Os medicamentos, assim como os alimentos deveriam ser tratados como bens ou produtos de primeira necessidade e, portanto, de exceção, não sujeitos às restrições de ordem patentária. Na medida em que são bens essenciais para o homem, não podem ser tratados como mercadorias comuns, sujeitos apenas à vontade de particulares ou de grandes corporações que, protegidas por patentes, ditam as regras de como, quanto, onde e quando produzir, fixando preços nesses produtos sem qualquer tipo de controle e tornando esses bens cada vez mais inacessíveis para um número crescente de pessoas. 
Essa é a proposta de Isidoro Moreno, professor de Antropologia Social da Universidade de Sevilha, ao sustentar que deve ser assegurado acesso universal a bens fundamentais como os alimentos, embora admita que a lógica que regulamenta esse processo não está baseada em princípios humanitários e é negada pelas políticas apoiadas pela OMC e pelo Banco Mundial. De acordo com proposta feita pelo professor Moreno, deveria se admitir que bens relacionados à manutenção da vida fossem considerados como "produtos de exceção" e submetidos a regras distintas daquelas que comandam a circulação de mercadorias no mundo. Com isso, esses produtos seriam incluídos numa agenda distinta daquela que vem sendo hoje negociada pelos governos no âmbito da OMC, já que "O princípio da soberania alimentar considera a alimentação como um direito humano básico que deveria estar presente nas políticas de todos os governos. A idéia da soberania alimentar implica, entre outras coisas, reconhecer o direito dos povos em produzir, em seus próprios países, os alimentos necessários para a sua sobrevivência"(23).

Hoje, tanto um medicamento para tratar uma doença crônica quanto uma máquina fotográfica digital estão no mesmo nível de proteção patentária. Comprar uma máquina fotográfica - um bem supérfluo - de um modelo ou de uma marca é uma questão de opção e de capacidade econômica, mas consumir um medicamento quando ele é o único disponível no mundo para o tratamento de uma doença é questão de necessidade vital que deve merecer proteção jurídica diferenciada. Ou seja, ambas as hipóteses não deveriam receber o mesmo tratamento jurídico, na medida em que a disponibilidade e o acesso a esses produtos resultam em necessidades e conseqüências distintas para seus usuários.

Diante das regras do acordo TRIPS esses objetivos têm sido desviados e, embora os titulares das patentes desfrutem de monopólio, não são obrigados a produzir localmente o objeto de suas patentes, podendo optar, como dissemos, pela importação do produto. Além disso, o monopólio permite ao titular da patente fixar no produto o preço que bem entender, sem qualquer tipo de controle social. Em razão de não haver concorrência, só existindo o produto protegido por patente para ser consumido pelo mercado, seu preço é fixado de acordo com critérios determinados exclusivamente pelo titular da patente.

A fixação do preço de um medicamento, num cenário de livre concorrência, orienta-se por critérios de mercado, ou seja, funciona com base na "lei da oferta e procura", que por sua vez condiciona a estratégia das empresas em reduzir custos para oferecer seus produtos a um preço cada vez mais competitivo em relação a seus concorrentes. No caso das patentes, o monopólio cria uma espécie de reserva de mercado, na qual somente o titular da

(23) AGÉNCIA Carta Maior. Disponivel em: <http://agenciacartamaior.uol.com.br/agencia.asp? $i d=2634 \&$ cd_editoria=001\&coluna=reportagens $>$. Acesso em:29.dez.2005. 
patente tem o direito de oferecer o produto. Assim "o preço é fixado pelo monopolista acima do que seria o preço num mercado de concorrência perfeita, o que acaba por excluir os consumidores ... o que, em se tratando de medicamentos essenciais, tem resultados desastrosos ao privar milhões de pacientes de tratamento adequado. Aí está, portanto, o problema: o exercício racional do poder de monopólio conduz à elevação dos preços e ao não atendimento das necessidades de consumidores que não podem pagar o preço mais elevado, sem que se possa caracterizar, aqui, o abuso do direito de patente (já que a elevação do preço está baseada na racionalidade do modelo econômico). A resposta jurídica a esse problema não deve, assim, basear-se na teoria do abuso de direito pelo titular da patente farmacêutica"(24).

Com relação à quantidade do produto, por exemplo, a hipótese de desabastecimento pode dar ensejo ao abuso do direito de patente por seu titular e existem dispositivos que, mesmo de eficácia questionável, são destinados a coibir essa prática, como é o caso da licença compulsória. Mas, no tocante à fixação do preço de um produto protegido por patente, qualquer que seja esse produto, não há nenhum tipo de mecanismo de controle para questionar ou coibir eventuais abusos por parte dos titulares das patentes. Uma das justificativas que sustentam a manutenção do sistema de patentes é a necessidade de remunerar os titulares das patentes pelos investimentos efetuados com pesquisa e desenvolvimento da invenção, embora não haja obrigatoriedade na divulgação desses investimentos e os gastos com publicidade do produto superem muitas vezes os gastos com pesquisa e desenvolvimento.

Essa situação gera uma grande distorção no mercado, em prejuízo de toda a sociedade. A obtenção de uma patente representa, na prática, um poder quase absoluto para o titular da patente que, por no mínimo 20 anos, pode definir o preço e as condições em que o produto patenteado será oferecido, se será produzido localmente ou importado. Nesse sentido, não há uma relação direta e equilibrada entre o investimento feito em uma invenção e o potencial de exploração econômica do produto objeto dessa invenção, pois o preço do produto patenteado e o prazo mínimo de uma patente (vinte anos) formam uma equação cujo resultado não é transparente para a sociedade. Se o preço do produto patenteado é uma variável controlada exclusivamente pelo titular da patente e se existe um prazo de proteção de pelo menos vinte anos, como aferir se o retorno econômico da exploração da patente para seu titular não causa mais prejuízos do que benefícios para a sociedade?

Em 1992, antes mesmo da aprovação do acordo TRIPS e das discussões sobre patentes farmacêuticas ganharem dimensão internacional, Jorge Bermudez já chamava a atenção sobre os aspectos restritivos das patentes:

(24) SANTOS, Denis Ishikawa dos. op. cit., p. 23-24. 
"As seguintes constatações foram evidenciadas no que se refere às patentes, em absoluto desacordo com as alegações das empresas multinacionais: as patentes não incentivam o investimento em pesquisa nas subsidiárias em países em desenvolvimento; as patentes não interferem na decisão do empresário sobre o investimento; as patentes representam um monopólio e favorecem a formação de trustes; as patentes não servem à revelação de segredos em tecnologia; as patentes podem provocar, por causa do monopólio, preços maiores, riscos no abastecimento, eliminação da concorrência, criação de mercados cativos, maior remessa de divisas e desigual distribuição da renda nacional; as patentes beneficiam exclusivamente as empresas que controlam o mercado de tecnologia".(25)

Nessa linha, com a justificativa de estimular as invenções e o desenvolvimento industrial, concede-se o monopólio da exploração da patente de qualquer produto pelo prazo de vinte anos, deixando em segundo plano a questão dos aspectos restritivos das patentes, que limitam ou impedem a sociedade de se beneficiar plenamente e de forma equilibrada dessas invenções. É preciso que se negocie uma estratégia global para criar mecanismos efetivos que facilitem a melhoria do acesso a medicamentos de forma permanente e não eventual.

Atualmente, a Organização Mundial da Saúde e as Nações Unidas desenvolvem estratégias e programas comuns para enfrentar as principais epidemias, como AIDS, malária e tuberculose, com base em critérios técnicos de longo prazo, cujo eixo principal é cooperação internacional. Porém, alguns países têm optado pela adoção de políticas unilaterais de doação de medicamentos que, embora cumpra uma função humanitária relevante e minimize a carência da população de países pobres por medicamentos, principalmente na África, são paliativas e não alteram a estrutura do problema.

Por esses motivos, entendemos que só será possível imaginar uma solução efetiva para superar carências estruturais dos países pobres com o estabelecimento de condições e tratamentos especiais a esses países, começando pela implementação de um processo objetivo de planejamento e cooperação internacional que, passa, necessariamente, pelo reforço - e não pelo esvaziamento - da atuação de organizações internacionais do porte e da credibilidade das Nações Unidas e da Organização Mundial da Saúde.

\section{REFERENCIAS}

AGÊNCIA Carta Maior. Dișponível em: <http://agenciacartamaior.uol.com.br/ agencia.asp?id=2634\&cd_editoria $=001 \&$ coluna=reportagens $>$. Acesso em: 29.dez.2005.

(25) BERMUDEZ, Jorge. Remédios: saúde ou indústria?: a produção de medicamentos no Brasil. Rio de Janeiro: Relume-Dumará, 1992. p. 73-74. 
ARAÚJO, Luiz Alberto David. A proteção constitucional das pessoas portadoras de deficiência. 2. ed. Brasília: Corde, 1997.

BARBOSA, Denis Borges. Uma introdução à propriedade intelectual. Rio de Janeiro: Lumen Juris, 1998. v. 1.

. Licenças compulsórias: abuso, emergência nacional e interesse público. Revista da $A B P I$, Rio de Janeiro, n. 45, mar./abr. 2000.

. A nova regulamentação da licença compulsória por interesse público. Revista da ABPI, Rio de Janeiro, n. 67, p. 10-33, nov./dez. 2003.

BASSO, Maristela. O direito internacional da propriedade intelectual. Porto Alegre: Livr. do Advogado, 2000.

BERMUDEZ, Jorge. Remédios: saúde ou indústria?: a produção de medicamentos no Brasil. Rio de Janeiro: Relume-Dumará, 1992.

BOBBIO, Norberto. A era dos direitos. Rio de Janeiro: Campus, 1992.

CASELLA, Paulo Borba. Resultados da Rodada Uruguai: aspectos legais e constitucionais de sua implementação no Brasil. In: CASELLA, Paulo Borba; MERCADANTE, Araminta de Azevedo (Coords.). Guerra comercial ou integração mundial pelo comércio?: a OMC e o Brasil. São Paulo: LTr, 1998.

CORREA, Carlos M. Acuerdo TRIPS: régimen internacional de la propiedad intelectual. Buenos Aires: Ediciones Ciudad Argentina, 1998.

- Implications of the Doha Declaration on the TRIPS Agreement and Public Health. In: WHO Health Economics and Drugs, EDM Series, n. 12, CID Working Paper, n. 92, Geneva, World Health Organization, 2002. Disponível em: <http://www.gefoodalert.org/library/admin/uploadedfiles/Implications_of_ the_Doha_Declaration_on_the_TR.htm>. Acesso em: 27.nov.2005.

DALLARI, Dalmo de Abreu. Direitos humanos e cidadania. São Paulo: Moderna, 1998.

Do patents for antiretroviral drugs constrain access to AIDS treatment in Africa? Disponível em <http://www.iipi.org/activities/Research/antiretroviral_ article.pdf>. Acesso em: 22.dez.2005.

GONTIJO, Cícero Ivan Ferreira. Propriedade industrial no século XXI. Direitos desiguais. Estudo realizado a pedido do Grupo de Trabalho de Propriedade Intelectual da Rede Brasileira pela Integração dos Povos - Rebrip, Instituto de Estudos Socioeconômicos - Inesc e Oxfam, jul. 2003.

. As transformações do sistema de patentes: da Convenção de Paris ao Acordo TRIPS: a posição brasileira. Brasília: Fundação Heinrich Böll, 2005. Disponível em: <http://www.rebrip.org.br/publique/media/trips.pdf>. Acesso em 12.dez.2005. 
Integrando Direitos de Propriedade Intelectual e Política de Desenvolvimento. Relatório elaborado pela Comissão para Direitos de Propriedade Intelectual do Ministério Desenvolvimento Internacional do Reino Unido. Londres, set. 2002. Disponivel em: <http://www.iprcommission.org>.

LOTROWSKA, Michel. Panorama internacional contemporâneo do acesso a anti-retroviral. In: PASSARELLI, Carlos André; PARKER, Richard; TERTO JR., Cristina Pimenta e Veriano (Orgs.). AIDS e desenvolvimento: interfaces $e$ políticas públicas. Rio de Janeiro: ABIA - Associação Brasileira Interdisciplinar de AIDS, 2003. p. 184-206.

Organização Mundial da Saúde. Fabricação de anti-retrovirais nos países em desenvolvimento e desafios para o futuro. Informe da Secretaria da Organização Mundial da Saúde, de 29 de abril de 2004, 114 reunião do Conselho Executivo. Disponível em: <http://www.who.int/gb/ebwha/pdf_files/EB114/ B114_15-sp.pdf>. Acesso em 24.out.2005.

PASSARELLI, Carlos André; PARKER, Richard; TERTO JR., Cristina Pimenta e Veriano (Orgs.). AIDS e desenvolvimento: interfaces e políticas públicas. Rio de Janeiro: ABIA - Associação Brasileira Interdisciplinar de AIDS, 2003.

SANTOS, Denis Ishikawa dos. Patentes farmacêuticas e acesso a medicamentos: da Rodada Uruguai à Declaração de Doha sobre o Acordo TRIPS e Saúde Pública. 2004. Tese (Tese Láurea - Curso de Graduação) - Faculdade de Direito, Universidade de São Paulo, São Paulo, 2004.

SOARES, Guido Fernando Silva. O tratamento da propriedade intelectual no Sistema da Organização Mundial do Comércio: uma descrição Geral do Acordo 'TRIPs'. In: CASELLA, Paulo Borba; MERCADANTE, Araminta de Azevedo (Coords.). Guerra comercial ou integração mundial pelo comércio?: a OMC e o Brasil. São Paulo: LTr, 1998. p. 660-689.

A Sustentabilidade do Acesso Universal a Anti-Retrovirais no Brasil. Documento elaborado pelo Ministério da Saúde, Programa Nacional de DST/AIDS, para divulgação durante a $157^{\mathrm{a}}$ Reunião Ordinária do Conselho Nacional de Saúde. Brasília, 10 de agosto de 2005. Disponível em: <www.aids.gov.br>. 